\title{
Accessory factors and the regulation of epithelial sodium channel activity
}

\author{
David G. Warnock \\ Department of Medicine, Department of Physiology and Biophysics, and Nephrology Research and \\ Training Center, University of Alabama at Birmingham, Birmingham, Alabama 35294-0007, USA
}

Address correspondence to: David G. Warnock, Division of Nephrology, University of Alabama at Birmingham,

UAB Station, Birmingham, Alabama 35294-0007, USA. Phone: (205) 934-3585; Fax: (205) 934-1879; E-mail: dwarnock@nrtc.dom.uab.edu

The contribution in this issue of the JCI by Abriel et al. (1) brings into sharp focus our expanding knowledge of the regulation of epithelial sodium channel $(\mathrm{ENaC})$ activity by specific accessory proteins. It has long been recognized that interactions with cytoskeletal proteins, such as actin, can regulate $\mathrm{ENaC}$ in a number of model systems (2). The interactions with defined cytosolic regions of the $\mathrm{ENaC}$ subunits were demonstrated by earlier studies of the ubiquitin ligase Nedd4 by Staub et al. (3). The importance of this interaction was emphasized by the finding that the site of interaction was with specific proline-rich regions of the subunits and that these very sites were found to be mutated, or even missing, in patients with Liddle's syndrome (4). This autosomal dominant syndrome is a rare cause of human hypertension that has clearly been shown to result from the failure to properly regulate $\mathrm{ENaC}$ expression and activity, with volume-expanded low-renin hypertension as the direct consequence.

It appears that Nedd 4 negatively modulates $\mathrm{ENaC}$ activity; binding of its WW domains to the proline domains of $\mathrm{ENaC}$ is followed by ubiquitination of the channel subunits, with subsequent endocytosis and lysosomal degradation. Indeed, $\mathrm{ENaC}$ appears to turn over quite rapidly with critical $\mathrm{NH}_{2}$-terminal lysine residues identified as the sites of ubiquitination of the $\alpha$ and $\gamma$ subunits (5). In the current studies, the Xenopus oocyte expression system was used to demonstrate that overexpression of Nedd4 with ENaC inhibited channel activity. This effect was critically dependent on the proline domains in the $\mathrm{ENaC}$ subunits and on intact ubiquitination activity of the Nedd 4 protein (1). Of note, a catalytically inactive
Nedd4 construct appeared to interact competitively with the wild-type Nedd 4 protein and actually protected the expressed $\mathrm{ENaC}$ from ubiquitination. $\mathrm{A}$ similar dependence of the regulatory effect of Nedd 4 on its $\mathrm{COOH}$-terminal ubiquitin ligase domain was recently demonstrated by Goulet et al. (6). These changes in $\mathrm{ENaC}$ activity can be rationalized in terms of changes in the surface expression of the channel complex, consistent with the role of the Nedd4 protein in endocytosis and degradation of the assembled $\mathrm{ENaC}$ complex at the surface membrane.

While these effects are clearly explained by changes in the surface expression the $\mathrm{ENaC}$ complexes, there also appear to be direct kinetic effects of the various mutations described in Liddle's syndrome on the apparent open probability of the expressed $\mathrm{ENaC}$ (7). Certainly, endocytosis plays an important role in determining channel density or dwell time in the surface membrane, but other factors may also affect the rate of endocytosis (8), and even exocytosis, of the assembled channel complex to the surface membrane $(9,10)$. Other factors, including K-Ras2A, a small $G$ protein that may in fact be one of the long-sought aldosterone-induced proteins (11), and an $\mathrm{ENaC}$-associated serine protease termed channel activating protein-1 (12) can activate $\mathrm{ENaC}$ activity independently of changes in its surface expression. In fact, K-Ras2A markedly increases in $\mathrm{ENaC}$ activity despite a decrease in surface expression (11), while we find that syntaxin $1 \mathrm{~A}$ increases $\mathrm{ENaC}$ surface expression but decreases functional $\mathrm{ENaC}$ activity (9).

This ensemble of studies has revealed important themes and details of the short-term regulation of $\mathrm{ENaC}$ activity.
Although these studies have relied heavily on the Xenopus oocyte expression system, it can be expected that these results will provide novel approaches to the understanding, and even therapy, of human disorders of $\mathrm{ENaC}$ regulation. As the panoply of accessory proteins and factors unfolds, each provides a new candidate for the exploration of the functional regulation of $\mathrm{ENaC}$ activity, and even potential genetic linkage approaches to defined subsets of human low-renin hypertension.

1. Abriel, H., et al. 1999. Defective regulation of the epithelial $\mathrm{Na}^{+}$channel by Nedd4 in Liddle's syndrome. J. Clin. Invest. 103:667-673.

2. Cantiello, H.F. 1995. Role of the actin cytoskeleton on epithelial $\mathrm{Na}^{+}$channel regulation. Kidney Int. 48:970-984.

3. Staub, O., et al. 1996. WW domains of Nedd4 bind to the proline-rich PY motifs in the epithelial $\mathrm{Na}^{+}$channel deleted in Liddle's syndrome. EMBO J. 15:2371-2380.

4. Warnock, D.G. 1998. Liddle syndrome: an autosomal dominant form of human hypertension. Kidney Int. 53:18-24.

5. Staub, O., et al. 1997. Regulation of stability and function of the epithelial $\mathrm{Na}^{+}$channel $(\mathrm{ENaC})$ by ubiquitination. EMBO J. 16:6325-6336.

6. Goulet, C.C., et al. 1998. Inhibition of the epithelial $\mathrm{Na}^{+}$channel by interaction of Nedd 4 with a PY motif deleted in Liddle's syndrome. J. Biol. Chem. 273:30012-30017.

7. Firsov, D., et al. 1996. Cell surface expression of the epithelial Na channel and a mutant causing Liddle syndrome: a quantitative approach. Proc. Natl. Acad. Sci. USA. 93:15370-15375.

8. Shimkets, R.A., Lifton, R.P., and Canessa, C.M. 1997. The activity of the epithelial sodium channel is regulated by clathrin-mediated endocytosis. J. Biol Chem. 272:25537-25541.

9. Saxena, S., Quick, M., and Warnock, D.G. 1998. Physical and functional interaction between $\mathrm{ENaC}$ and syntaxins. J. Am. Soc. Nephrol. 9:44. (Abstr.)

10. Peters, K.W., et al. 1998. Syntaxin $1 \mathrm{~A}$ inhibits functional expression of the amiloride-sensitive epithelial sodium channel. FASEB J. 12:981. (Abstr.)

11. Mastroberardino, L., et al. 1998. Ras pathway activates epithelial $\mathrm{Na}^{+}$channel and decreases its surface expression in Xenopus oocytes. Mol. Biol. Cell. 9:3417-3427.

12. Vallet, V., et al. 1997. An epithelial serine protease activates the amiloride-sensitive sodium channel. Nature. 389:607-610. 